Research Article

\title{
Chemical Reactivity Properties, Solubilities, and Bioactivity Scores of Some Pigments Derived from Carotenoids of Marine Origin through Conceptual DFT Descriptors
}

\author{
Norma Flores-Holguín (D), ${ }^{1}$ Juan Frau, ${ }^{2}$ and Daniel Glossman-Mitnik $\mathbb{D}^{1,2}$ \\ ${ }^{1}$ Laboratorio Virtual NANOCOSMOS, Centro de Investigación en Materiales Avanzados, \\ Departamento de Medio Ambiente y Energía, Chihuahua, Mexico \\ ${ }^{2}$ Universitat de les Illes Balears, Departament de Química, Palma de Mallorca, Spain \\ Correspondence should be addressed to Daniel Glossman-Mitnik; daniel.glossman@cimav.edu.mx
}

Received 6 May 2019; Revised 24 August 2019; Accepted 10 September 2019; Published 13 October 2019

Academic Editor: Franck Rabilloud

Copyright (C) 2019 Norma Flores-Holguín et al. This is an open access article distributed under the Creative Commons Attribution License, which permits unrestricted use, distribution, and reproduction in any medium, provided the original work is properly cited.

Five density functionals, CAM-B3LYP, LC- $\omega$ HPBE, MN12SX, N12SX, and $\omega$ B97XD, in connection with the Def2TZVP basis set were assessed together with the SMD solvation model for the calculation of the molecular properties, chemical reactivities, and solubilities of some pigments derived from astaxanthin, $\beta$-cryptoxanthin, fucoxanthin, myxol, siphonaxanthin, siphonein, and zeaxanthin marine carotenoids in the presence of different solvents (hexane, methanol, ethanol, and water). All the chemical reactivity descriptors for the systems were calculated via conceptual density functional theory (CDFT). Finally, the potential bioavailability and druggability as well as the bioactivity scores for the marine carotenoid pigments were predicted through different methodologies already reported in the literature, which have been previously validated during the study of other natural products obtained from marine sources.

\section{Introduction}

Carotenoids are pigments widely found in nature, either in plants, animals, or microorganisms, forming a group consisting of over 700 compounds. Carotenoids stand as the major group of compounds used as color additives. These natural pigments are responsible for many of the colors seen in edible fruits, vegetables, mushrooms, flowers, and even lobster and trout hues from the animal kingdom [1].

Due to their inherent coloration, these pigments have been proven to be useful as food colorants [2] and as sensitizers for applications in organic photovoltaic solar cells and artificial photosynthesis [3]. Our group has earlier performed computational chemistry and molecular modeling studies on some carotenoid pigments that could be potentially considered to be the energy absorbing material of dye-sensitized solar cells [4-6]. Additionally, these compounds function as sources of provitamin A, are capable of absorbing sunlight, and can act as oxygen transporters, powerful quenchers of singlet oxygen, and free radical scavengers.
Marine-derived bioactive compounds offer an abundant source of pharmacologically active agents with great chemical diversity and complexity and the potential to produce valuable therapeutic entities [7]. Due to this, a lot of research has been performed during the last two decades dedicated to the search for new natural products that can be acquired from the knowledge of species of marine origin through the field of marine pharmacognosy [8].

Among the chemical species that can be obtained from natural products of marine origin, carotenoid pigments are molecules of relatively small size. The therapeutic application of these pigments is currently an active field of research because they could have a strong potential for the treatment of several ailments $[9,10]$.

In order to consider these carotenoid pigments as the starting point for the development of medical drugs, it is mandatory to acquire knowledge about their chemical reactivity properties as well as the bioactivity associated with them. From the basics of medicinal chemistry, it is known that drugs exert their effect by interacting with the active site 
of a receptor, which is generally a protein [11]. These interactions rely on the different kinds of bindings between the pharmacophore and the chemical groups present in the active site and thus are intimately related to their chemical reactivity from a molecular perspective $[12,13]$. One of the most powerful tools to understand the chemical reactivity of interacting molecular systems within computational chemistry is probably conceptual DFT (density functional theory) $[14,15]$, also called chemical reactivity theory, which allows us to accomplish this task by resorting to several global and local descriptors which are in turn related to variations in the electronic densities of the studied systems.

On the basis of previous considerations, the objective of this work is to study the chemical reactivity of a group of carotenoids of marine origin, astaxanthin, $\beta$-cryptoxanthin, fucoxanthin, myxol, siphonaxanthin, siphonein, and zeaxanthin, which are representative of the most abundant xanthophylls present in ocean plants and animals, using the techniques of conceptual DFT, determining their global reactivity properties, that is, of the molecule as a whole. Moreover, during the process of development of new drugs, there is a need to learn about the drug-like properties of the involved molecular systems [16]. Thus, the descriptors of bioavailability and bioactivity (bioactivity scores) will be calculated through different procedures described in the literature $[17,18]$, trying to relate them with the calculated conceptual DFT descriptors.

\section{Computational Methodology}

In the same way as we have proceeded in our recent studies [19-28], the computational tasks in this work have been performed by considering the popular Gaussian 09 software [29]. Following the conclusions obtained from those studies, five density functionals have been chosen, CAM-B3LYP, LC$\omega \mathrm{HPBE}, \mathrm{MN} 12 \mathrm{SX}$ [30], N12SX, and $\omega \mathrm{B} 97 \mathrm{XD}$, because they can be considered to be well suited for our purposes according to our proposed KID (for Koopmans in DFT) criteria [19-28]. For the calculation of the electronic properties, several model chemistries have been considered, based on the mentioned density functionals in connection with the Def2TZVP basis set, while a smaller Def2SVP was considered for the prediction of the most stable structures $[31,32]$. In order to obtain accurate results, all calculations were performed using four different solvents, namely hexane, methanol, ethanol, and water, simulated with the SMD model [33]. While water is the universal biological solvent, the others were chosen because a good solvent selection is necessary for easy and effective synthesis of compounds used in drugs.

\section{Results and Discussion}

The molecular structures of the optimized conformers of the seven carotenoids of marine origin as presented in Figure 1 were optimized in the gas phase by means of the DFTBA model available in the software and then reoptimized with the five density functionals described previously, the Def2SVP basis set, and hexane, methanol, ethanol, or water as the solvent. The calculation of the electronic properties was performed by using the same model chemistries but changing the basis set with the Def2TZVP one.

In order to verify the fulfillment of our proposed KID procedure, it is necessary to perform a comparison of the orbital energies with the results obtained by means of vertical $I$ and $A$ through the $\triangle \mathrm{SCF}$ criterion. To this end, the three main descriptors are linked as $\epsilon_{H}$ with $-I$ and $\epsilon_{L}$ with $-A$, and their behavior in describing the HOMO-LUMO gap is defined as $J_{I}=\left|\epsilon_{H}+E_{\mathrm{gs}}(N-1)-E_{\mathrm{gs}}(N)\right|, J_{A}=\mid \epsilon_{L}+E_{\mathrm{gs}}(N)$ $-E_{\mathrm{gs}}(N+1) \mid$, and $J_{H L}=\sqrt{J_{I}^{2}+J_{A}^{2}}$. Another descriptor, $\Delta S L$, the difference between the SOMO and LUMO, was also designed to guide the verification of the accuracy of approximation $[19-25,27,28]$. The results of this analysis are presented in Tables 1-4.

The overall conclusion that can be extracted from the inspection of the results presented in Tables 1-4 is that in agreement with our previous studies on melanoidins and peptides, the model chemistries involving the MN12SX and N12SX density functionals are the best for verifying our proposed criteria of good behavior, that is, the values of $J_{I}$, $J_{A}, J_{H L}$, and $\Delta S L$ are close to zero. Moreover, it can be seen that the KID procedure is better verified for the case of the polar solvents rather than for hexane.

It is possible to obtain additional information about the solubility of these carotenoid pigments by means of the calculation of the free energy of solvation in every solvent according to each of the model chemistries. The results are presented in Table 5, where it can be seen that while all the carotenoid pigments are soluble in all solvents, their relative solubility is greater in methanol, ethanol, and hexane than in water. As it can be observed from this table, $\beta$-cryptoxanthin has the lowest solvation energy in water. This particular molecule has only one hydroxyl and its polarity is lower than that from the other analyzed systems.

\section{Calculation of Global Reactivity Descriptors}

By taking into account the KID procedure presented in our previous works together with the finite difference approximation, the global reactivity descriptors can be expressed as follows:

$$
\begin{aligned}
& \text { Electronegativity: } \chi=-(1 / 2)(I+A) \approx(1 / 2)\left(\epsilon_{L}+\epsilon_{H}\right) \\
& {[14,15]} \\
& \text { Global Hardness: } \eta=(I-A) \approx\left(\epsilon_{L}-\epsilon_{H}\right)[14,15] \\
& \text { Electrophilicity: } \omega=\left(\mu^{2} / 2 \eta\right)=\left((I+A)^{2} / 4(I-A)\right) \approx \\
& \left(\left(\epsilon_{L}+\epsilon_{H}\right)^{2} / 4\left(\epsilon_{L}-\epsilon_{H}\right)\right)[34] \\
& \text { Electrodonating power: } \omega^{-}=\left((3 I+A)^{2} / 16(I-A)\right) \approx \\
& \left(\left(3 \epsilon_{H}+\epsilon_{L}\right)^{2} / 16 \eta\right)[35] \\
& \text { Electroaccepting power: } \omega^{+}=\left((I+3 A)^{2} / 16(I-A)\right) \approx \\
& \left(\left(\epsilon_{H}+3 \epsilon_{L}\right)^{2} / 16 \eta\right)[35]
\end{aligned}
$$$$
\text { Net electrophilicity: } \Delta \omega^{ \pm}=\omega^{+}-\left(-\omega^{-}\right)=\omega^{+}+\omega^{-} \text {[36] }
$$

Where $\epsilon_{H}$ and $\epsilon_{L}$ are the energies of the HOMO and LUMO, respectively.

The results for the global reactivity descriptors for the carotenoids pigments considered in this study based on the 


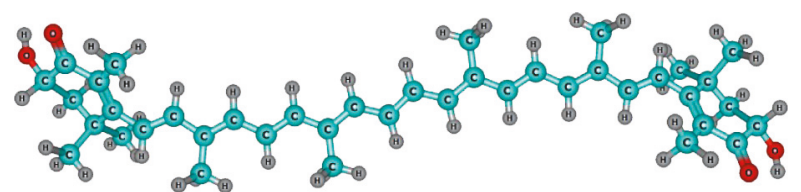

(a)

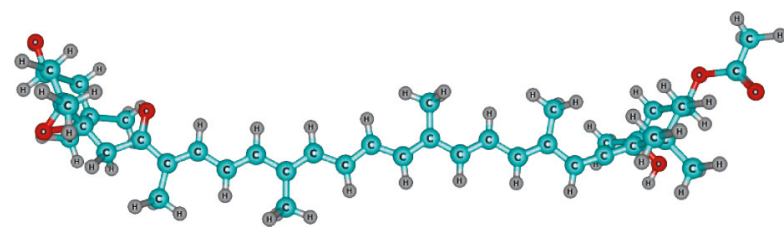

(c)

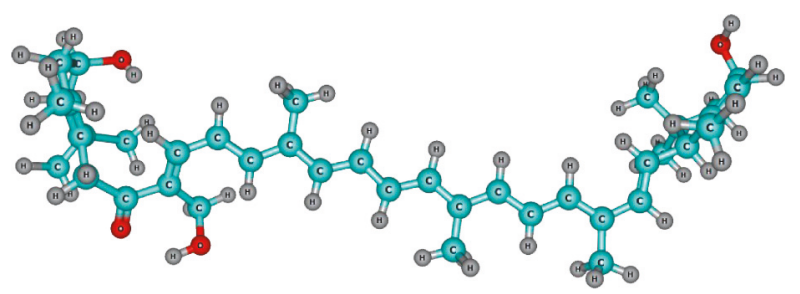

(e)

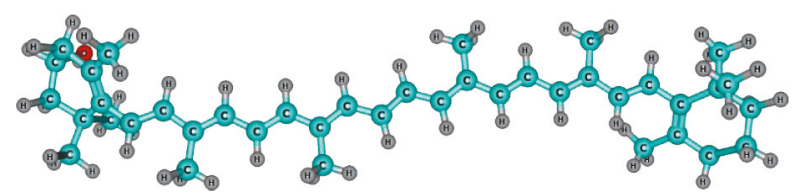

(b)

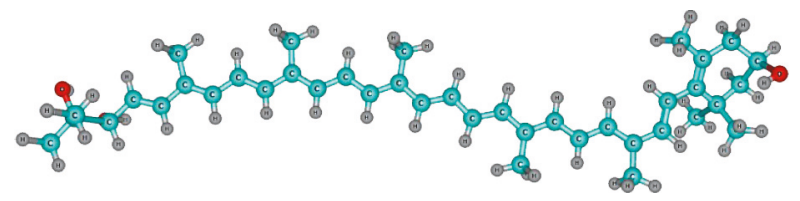

(d)

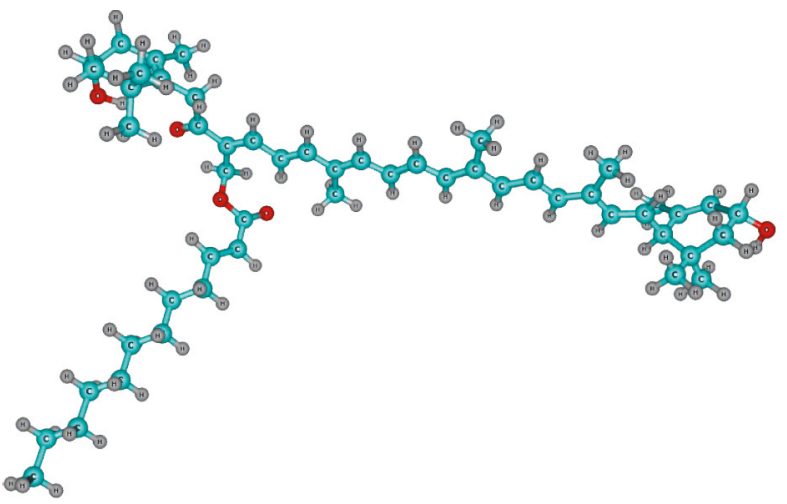

(f)

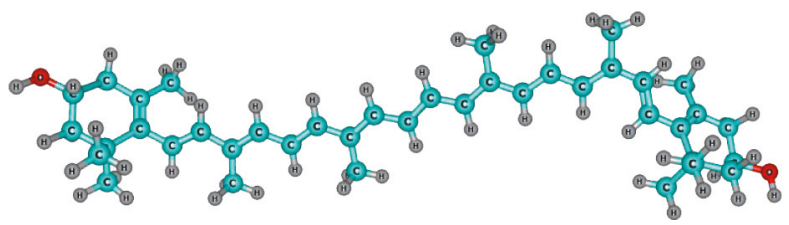

(g)

FIGURE 1: Graphical sketches of the molecular structures of the carotenoid pigments of marine origin: (a) astaxanthin; (b) $\beta$-cryptoxanthin; (c) fucoxanthin; (d) myxol; (e) siphonaxanthin; (f) siphonein; (g) zeaxanthin.

values of the HOMO and LUMO energies calculated with the five density functionals are presented in Tables 6-12:

As expected from the molecular structure of these carotenoids, their electrodonating ability is more important that their electroaccepting character. However, on comparing the results for global hardness and electrophilicity of all the systems in the four solvents, it can be seen that MN12SX and N12SX density functionals (which verify the KID criteria) give results different from those obtained from calculation with the other three density functionals. It is also well known that the MN12SX density functional has the best across-the-board performance of all the considered functionals for chemistry and physics and for energies and structures.

The electrophilicity $(\omega)$ index encompasses the balance between the tendency of an electrophile to acquire an extra magnitude of electron density and the resistance of a molecule to exchange electron density with the environment [37]. By studying the electrophilicity of a series of reagents involved in Diels-Alder reactions [38], through quantitative characterization of the global electrophilicity pattern of some reagents involved in 1,3-dipolar cycloaddition reactions [39], and by means of understanding of the mechanism of polar DielsAlder reactions [40], Domingo et al. established an electrophilicity $(\omega)$ scale for the classification of organic molecules as strong electrophiles with $\omega>1.5 \mathrm{eV}$, moderate electrophiles with $0.8<\omega<1.5 \mathrm{eV}$, and marginal electrophiles with $\omega<0.8 \mathrm{eV}$ [38].

By inspection of Tables 7-12, it can be seen that all the carotenoids considered in this study can be regarded as strong electrophiles, irrespective of the solvents in which the calculations have been performed. The values for the global electrophilicity obtained by using the N12SX density functional are a little smaller than those achieved with the MN12SX density functional, but the conclusions are the same. Besides the electrophilicity classification, an electrophilicity scale for the marine carotenoids can be displayed as follows: myxol $>$ astaxanthin $>$ siphonaxanthin $>$ siphonein $>$ fucoxanthin $>$ zeaxanthin $>\beta$-cryptoxanthin, which is the same for the case of both density functionals and the four solvents considered here.

The nucleophilicity $\mathrm{N}$ is another important chemical reactivity descriptor. There are several definitions of 
TABLE 1: HOMO, LUMO, and SOMO orbital energies (in eV) and the KID-related descriptors obtained with the five density functionals, the Def2TZVP basis set, and hexane as the solvent.

\begin{tabular}{|c|c|c|c|c|c|c|c|}
\hline \multicolumn{8}{|c|}{ CAM-B3LYP } \\
\hline Molecule & HOMO & LUMO & SOMO & $J_{I}$ & $J_{A}$ & $J_{H L}$ & $\Delta S L$ \\
\hline Astaxanthin & -5.90 & -1.79 & -2.68 & 0.49 & 0.42 & 0.65 & 0.90 \\
\hline$\beta$-Cryptoxanthin & -5.56 & -1.34 & -2.29 & 0.46 & 0.46 & 0.66 & 0.95 \\
\hline Fucoxanthin & -5.98 & -1.60 & -2.51 & 0.49 & 0.44 & 0.66 & 0.91 \\
\hline Myxol & -5.47 & -1.63 & -2.63 & 0.50 & 0.50 & 0.71 & 1.00 \\
\hline Siphonaxanthin & -5.96 & -1.74 & -2.66 & 0.50 & 0.46 & 0.67 & 0.91 \\
\hline Siphonein & -5.95 & -1.63 & -2.53 & 0.49 & 0.45 & 0.66 & 0.91 \\
\hline Zeaxanthin & -5.58 & -1.42 & -2.36 & 0.47 & 0.47 & 0.66 & 0.95 \\
\hline \multicolumn{8}{|c|}{$L C-\omega H P B E$} \\
\hline Astaxanthin & -7.05 & -0.98 & -3.71 & 1.49 & 1.32 & 1.99 & 2.73 \\
\hline$\beta$-Cryptoxanthin & -6.75 & -0.57 & -3.38 & 1.43 & 1.39 & 2.00 & 2.80 \\
\hline Fucoxanthin & -7.14 & -0.80 & -3.57 & 1.48 & 1.38 & 2.02 & 2.76 \\
\hline Myxol & -6.65 & -0.85 & -3.71 & 1.52 & 1.47 & 2.11 & 2.87 \\
\hline Siphonaxanthin & -7.12 & -0.94 & -3.70 & 1.51 & 1.41 & 2.06 & 2.76 \\
\hline Siphonein & -7.12 & -0.83 & -3.59 & 1.49 & 1.39 & 2.03 & 2.76 \\
\hline Zeaxanthin & -6.77 & -0.63 & -3.45 & 1.44 & 1.41 & 2.02 & 2.81 \\
\hline \multicolumn{8}{|c|}{$M N 12 S X$} \\
\hline Astaxanthin & -4.94 & -3.18 & -2.03 & 0.61 & 0.58 & 0.84 & 1.15 \\
\hline$\beta$-Cryptoxanthin & -4.53 & -2.69 & -1.45 & 0.61 & 0.62 & 0.87 & 1.24 \\
\hline Fucoxanthin & -4.94 & -2.98 & -1.63 & 0.67 & 0.67 & 0.95 & 1.35 \\
\hline Myxol & -4.47 & -2.97 & -1.78 & 0.60 & 0.59 & 0.84 & 1.19 \\
\hline Siphonaxanthin & -4.94 & -3.12 & -1.77 & 0.69 & 0.67 & 0.96 & 1.35 \\
\hline Siphonein & -4.93 & -3.01 & -1.66 & 0.68 & 0.67 & 0.96 & 1.35 \\
\hline Zeaxanthin & -4.55 & -2.76 & -1.53 & 0.61 & 0.62 & 0.87 & 1.23 \\
\hline \multicolumn{8}{|c|}{ N12SX } \\
\hline Astaxanthin & -4.70 & -2.98 & -1.86 & 0.57 & 0.56 & 0.80 & 1.12 \\
\hline$\beta$-Cryptoxanthin & -4.29 & -2.53 & -1.29 & 0.58 & 0.59 & 0.83 & 1.19 \\
\hline Fucoxanthin & -4.71 & -2.79 & -1.49 & 0.63 & 0.65 & 0.91 & 1.30 \\
\hline Myxol & -4.23 & -2.76 & -1.62 & 0.56 & 0.56 & 0.79 & 1.14 \\
\hline Siphonaxanthin & -4.71 & -2.93 & -1.62 & 0.65 & 0.65 & 0.91 & 1.30 \\
\hline Siphonein & -4.69 & -2.82 & -1.51 & 0.64 & 0.65 & 0.91 & 1.30 \\
\hline Zeaxanthin & -4.30 & -2.55 & -1.37 & 0.58 & 0.59 & 0.83 & 1.18 \\
\hline \multicolumn{8}{|c|}{$\omega B 97 X D$} \\
\hline Astaxanthin & -6.44 & -1.32 & -3.18 & 0.97 & 0.89 & 1.32 & 1.86 \\
\hline$\beta$-Cryptoxanthin & -6.11 & -0.88 & -2.79 & 0.94 & 0.94 & 1.33 & 1.92 \\
\hline Fucoxanthin & -6.52 & -1.13 & -3.02 & 0.98 & 0.93 & 1.35 & 1.89 \\
\hline Myxol & -6.01 & -1.15 & -3.13 & 0.98 & 0.97 & 1.38 & 1.98 \\
\hline Siphonaxanthin & -6.50 & -1.26 & -3.17 & 0.99 & 0.94 & 1.37 & 1.90 \\
\hline Siphonein & -6.50 & -1.15 & -3.04 & 0.98 & 0.93 & 1.35 & 1.89 \\
\hline Zeaxanthin & -6.12 & -0.94 & -2.86 & 0.95 & 0.94 & 1.34 & 1.92 \\
\hline
\end{tabular}

nucleophilicity available in the literature of conceptual DFT, and the interested reader is referred to the recent work of Domingo and Pérez [41]. However, these indices fail for more complex molecules which display concurrently both electrophilic and nucleophilic behaviors, and in these cases, the value of electrophilicity $(\omega)$ does not correlate well with their expected nucleophilicity [37, 42]. This has compelled Domingo and his collaborators [37, 40-43] to propose a new nucleophilicity index, $\mathrm{N}$, simply based on the highest occupied molecular orbital (HOMO) energy obtained within the Kohn-Sham scheme with an arbitrary shifting of the origin with tetracyanoethylene (TCE) taken as a reference. The corresponding definition for the nucleophilicity $(\mathrm{N})$ index is $N_{(N u)}=$ $E_{\mathrm{HOMO}(\mathrm{Nu})}-E_{\mathrm{HOMO}(\mathrm{TCE})}[37,40-43]$, and the results for the calculation of this index for the marine carotenoids using the MN12SX and N12SX density functionals are presented in Table 13.

On the basis of the previous definition and the scale established in the mentioned study [43], it can be concluded that all the marine carotenoids considered within this research can be regarded as strong nucleophiles because their values are greater than $3 \mathrm{eV}$, independent of the methodology employed for the calculations and the solvent considered in each case. However, the nucleophilic character for all the marine carotenoids is slightly greater in hexane than in the polar solvents (methanol, ethanol, and water).

\section{Bioactivity Scores}

The molecular properties that are related to the concept of drug-likeness and in particular, those associated with the 
TABLE 2: HOMO, LUMO, and SOMO orbital energies (in $\mathrm{eV}$ ) and the KID-related descriptors obtained with the five density functionals, the Def2TZVP basis set, and methanol as the solvent.

\begin{tabular}{|c|c|c|c|c|c|c|c|}
\hline \multicolumn{8}{|c|}{ CAM-B3LYP } \\
\hline Molecule & HOMO & LUMO & SOMO & $J_{I}$ & $J_{A}$ & $J_{H L}$ & $\Delta S L$ \\
\hline Astaxanthin & -5.78 & -1.68 & -3.79 & 1.14 & 1.02 & 1.52 & 2.11 \\
\hline$\beta$-Cryptoxanthin & -5.61 & -1.39 & -3.65 & 1.10 & 1.11 & 1.57 & 2.26 \\
\hline Fucoxanthin & -5.90 & -1.56 & -3.88 & 1.18 & 1.14 & 1.64 & 2.32 \\
\hline Myxol & -5.48 & -1.63 & -3.92 & 1.13 & 1.13 & 1.60 & 2.29 \\
\hline Siphonaxanthin & -5.86 & -1.67 & -3.99 & 1.21 & 1.16 & 1.68 & 2.32 \\
\hline Siphonein & -5.90 & -1.62 & -3.97 & 1.19 & 1.17 & 1.67 & 2.35 \\
\hline Zeaxanthin & -5.59 & -1.42 & -3.68 & 1.11 & 1.12 & 1.57 & 2.26 \\
\hline \multicolumn{8}{|c|}{$L C-\omega H P B E$} \\
\hline Astaxanthin & -6.76 & -0.91 & -4.95 & 2.17 & 1.97 & 2.93 & 4.05 \\
\hline$\beta$-Cryptoxanthin & -6.82 & -0.65 & -4.85 & 2.11 & 2.08 & 2.97 & 4.20 \\
\hline Fucoxanthin & -7.10 & -0.79 & -5.07 & 2.20 & 2.24 & 3.06 & 4.28 \\
\hline Myxol & -6.69 & -0.88 & -5.13 & 2.20 & 2.15 & 3.07 & 4.25 \\
\hline Siphonaxanthin & -7.06 & -0.89 & -5.19 & 2.25 & 2.18 & 3.13 & 4.30 \\
\hline Siphonein & -7.10 & -0.85 & -5.20 & 2.22 & 2.18 & 3.12 & 4.35 \\
\hline Zeaxanthin & -6.81 & -0.67 & -4.88 & 2.13 & 2.09 & 2.98 & 4.20 \\
\hline \multicolumn{8}{|c|}{ MN12SX } \\
\hline Astaxanthin & -4.82 & -3.08 & -3.05 & 0.01 & 0.02 & 0.02 & 0.03 \\
\hline$\beta$-Cryptoxanthin & -4.60 & -2.75 & -2.73 & 0.02 & 0.01 & 0.02 & 0.02 \\
\hline Fucoxanthin & -4.89 & -2.96 & -2.93 & 0.01 & 0.02 & 0.00 & 0.03 \\
\hline Myxol & -4.50 & -2.98 & -2.97 & 0.01 & 0.00 & 0.01 & 0.01 \\
\hline Siphonaxanthin & -4.86 & -3.06 & -3.04 & 0.01 & 0.01 & 0.02 & 0.02 \\
\hline Siphonein & -4.90 & -3.02 & -2.99 & 0.01 & 0.01 & 0.02 & 0.03 \\
\hline Zeaxanthin & -4.58 & -2.79 & -2.77 & 0.02 & 0.01 & 0.02 & 0.02 \\
\hline \multicolumn{8}{|c|}{ N12SX } \\
\hline Astaxanthin & -4.58 & -2.89 & -2.89 & 0.03 & 0.00 & 0.03 & 0.00 \\
\hline$\beta$-Cryptoxanthin & -4.36 & -2.56 & -2.60 & 0.01 & 0.02 & 0.03 & 0.04 \\
\hline Fucoxanthin & -4.66 & -2.78 & -2.80 & 0.03 & 0.01 & 0.03 & 0.02 \\
\hline Myxol & -4.26 & -2.78 & -2.84 & 0.03 & 0.03 & 0.04 & 0.06 \\
\hline Siphonaxanthin & -4.63 & -2.87 & -2.91 & 0.03 & 0.03 & 0.04 & 0.04 \\
\hline Siphonein & -4.66 & -2.83 & -2.86 & 0.03 & 0.02 & 0.04 & 0.03 \\
\hline Zeaxanthin & -4.34 & -2.58 & -2.63 & 0.02 & 0.03 & 0.03 & 0.05 \\
\hline \multicolumn{8}{|c|}{$\omega B 97 X D$} \\
\hline Astaxanthin & -6.34 & -1.23 & -4.32 & 1.62 & 1.49 & 2.20 & 3.09 \\
\hline$\beta$-Cryptoxanthin & -6.17 & -0.95 & -4.18 & 1.58 & 1.59 & 2.24 & 3.23 \\
\hline Fucoxanthin & -6.47 & -1.11 & -4.42 & 1.67 & 1.63 & 2.33 & 3.31 \\
\hline Myxol & -6.04 & -1.18 & -4.44 & 1.61 & 1.61 & 2.28 & 3.27 \\
\hline Siphonaxanthin & -6.43 & -1.21 & -4.53 & 1.71 & 1.65 & 2.37 & 3.32 \\
\hline Siphonein & -6.47 & -1.17 & -4.52 & 1.69 & 1.65 & 2.30 & 3.35 \\
\hline Zeaxanthin & -6.16 & -0.97 & -4.21 & 1.60 & 1.60 & 2.25 & 3.24 \\
\hline
\end{tabular}

criteria proposed by Lipinski et al. [44, 45] for the prediction of oral bioavailability have been calculated by feeding the Iponding SMILES notations into the MolInspiration software readily available online (Slovensky Grob, Slovak Republic (http://www.molinspiration.com)). The results are presented in Table 14.

However, what the Lipinski's rule of five really measures is the oral bioavailability of a potential drug because this is the desired property for a molecule having drug-like character. Then, a different approach was followed by considering similarity searches in the chemical space of compounds with structures that can be compared to those that are being studied and with known pharmacological properties. The same software was used for the calculation of the bioactivity scores which are a measure of the ability of the potential drug to interact with different receptors, that is, to act as GPCR ligands or kinase inhibitors, to perform as ion channel modulators, or to interact with enzymes and nuclear receptors. These predicted bioactivity scores were compared with those resulting from the use of alternative software like MolSoft from Molsoft LLC. (San Diego, CA, USA) (http:// molsoft.com/mprop/) as well as ChemDoodle Version 9.02 from iChemLabs LLC, Richmond, VA, USA (http://www. chemdoodle.com). The values of the bioactivity scores for the seven carotenoid pigments are presented in Table 15.

These bioactivity scores for organic molecules can be interpreted as active (when the bioactivity score $>0$ ), moderately active (when the bioactivity score lies between -5.0 and 0.0 ), and inactive (when the bioactivity score $<-5.0$ ). Thus, astaxanthin, $\beta$-cryptoxanthin, myxol, siphonaxanthin, 
TABLE 3: HOMO, LUMO, and SOMO orbital energies (in eV) and the KID-related descriptors obtained with the five density functionals, the Def2TZVP basis set, and ethanol as the solvent.

\begin{tabular}{|c|c|c|c|c|c|c|c|}
\hline \multicolumn{8}{|c|}{ CAM-B3LYP } \\
\hline Molecule & HOMO & LUMO & SOMO & $J_{I}$ & $J_{A}$ & $J_{H L}$ & $\Delta S L$ \\
\hline Astaxanthin & -5.78 & -1.68 & -3.77 & 1.12 & 1.01 & 1.51 & 2.09 \\
\hline$\beta$-Cryptoxanthin & -5.61 & -1.39 & -3.62 & 1.09 & 1.10 & 1.55 & 2.23 \\
\hline Fucoxanthin & -5.90 & -1.55 & -3.83 & 1.16 & 1.12 & 1.62 & 2.28 \\
\hline Myxol & -5.47 & -1.63 & -3.89 & 1.12 & 1.12 & 1.58 & 2.26 \\
\hline Siphonaxanthin & -5.86 & -1.66 & -3.95 & 1.19 & 1.14 & 1.65 & 2.29 \\
\hline Siphonein & -5.90 & -1.61 & -3.92 & 1.18 & 1.14 & 1.64 & 2.31 \\
\hline Zeaxanthin & -5.59 & -1.42 & -3.65 & 1.10 & 1.10 & 1.55 & 2.23 \\
\hline \multicolumn{8}{|c|}{$L C-\omega H P B E$} \\
\hline Astaxanthin & -6.96 & -0.90 & -4.92 & 2.16 & 1.96 & 2.91 & 4.02 \\
\hline$\beta$-Cryptoxanthin & -6.82 & -0.65 & -4.82 & 2.10 & 2.07 & 2.95 & 4.17 \\
\hline Fucoxanthin & -7.10 & -0.78 & -5.01 & 2.19 & 2.10 & 3.04 & 4.23 \\
\hline Myxol & -6.68 & -0.88 & -5.10 & 2.18 & 2.14 & 3.05 & 4.22 \\
\hline Siphonaxanthin & -7.06 & -0.88 & -5.13 & 2.24 & 2.15 & 3.10 & 4.25 \\
\hline Siphonein & -7.10 & -0.83 & -5.13 & 2.21 & 2.16 & 3.09 & 4.30 \\
\hline Zeaxanthin & -6.80 & -0.67 & -4.85 & 2.11 & 2.08 & 2.96 & 4.17 \\
\hline \multicolumn{8}{|c|}{ MN12SX } \\
\hline Astaxanthin & -4.81 & -3.07 & -3.02 & 0.02 & 0.03 & 0.03 & 0.06 \\
\hline$\beta$-Cryptoxanthin & -4.60 & -2.75 & -2.70 & 0.03 & 0.02 & 0.04 & 0.04 \\
\hline Fucoxanthin & -4.89 & -2.95 & -2.89 & 0.03 & 0.03 & 0.04 & 0.06 \\
\hline Myxol & -4.49 & -2.98 & -2.95 & 0.03 & 0.02 & 0.03 & 0.03 \\
\hline Siphonaxanthin & -4.85 & -3.05 & -3.00 & 0.02 & 0.03 & 0.04 & 0.05 \\
\hline Siphonein & -4.89 & -3.00 & -2.94 & 0.03 & 0.03 & 0.04 & 0.06 \\
\hline Zeaxanthin & -4.57 & -2.78 & -2.74 & 0.03 & 0.02 & 0.03 & 0.04 \\
\hline \multicolumn{8}{|c|}{ N12SX } \\
\hline Astaxanthin & -4.58 & -2.88 & -2.86 & 0.02 & 0.01 & 0.02 & 0.02 \\
\hline$\beta$-Cryptoxanthin & -4.36 & -2.55 & -2.57 & 0.00 & 0.01 & 0.01 & 0.02 \\
\hline Fucoxanthin & -4.66 & -2.76 & -2.76 & 0.02 & 0.00 & 0.01 & 0.01 \\
\hline Myxol & -4.26 & -2.78 & -2.81 & 0.01 & 0.02 & 0.02 & 0.03 \\
\hline Siphonaxanthin & -4.62 & -2.87 & -2.87 & 0.02 & 0.01 & 0.02 & 0.01 \\
\hline Siphonein & -4.65 & -2.82 & -2.81 & 0.02 & 0.00 & 0.02 & 0.00 \\
\hline Zeaxanthin & -4.34 & -2.58 & -2.61 & 0.00 & 0.02 & 0.02 & 0.02 \\
\hline \multicolumn{8}{|c|}{$\omega B 97 X D$} \\
\hline Astaxanthin & -6.33 & -1.22 & -4.29 & 1.61 & 1.48 & 2.18 & 0.25 \\
\hline$\beta$-Cryptoxanthin & -6.17 & -0.94 & -4.15 & 1.57 & 1.58 & 2.22 & 3.201 \\
\hline Fucoxanthin & -6.47 & -1.10 & -4.37 & 1.66 & 1.61 & 2.31 & 3.27 \\
\hline Myxol & -6.04 & -1.17 & -4.41 & 1.60 & 1.60 & 2.26 & 3.24 \\
\hline Siphonaxanthin & -6.43 & -1.20 & -4.49 & 1.69 & 1.63 & 2.35 & 3.28 \\
\hline Siphonein & -6.47 & -1.15 & -4.46 & 1.67 & 1.63 & 2.34 & 3.31 \\
\hline Zeaxanthin & -6.15 & -0.97 & -4.18 & 1.58 & 1.58 & 2.23 & 3.21 \\
\hline
\end{tabular}

TABLE 4: HOMO, LUMO, and SOMO orbital energies (in eV) and the KID-related descriptors obtained with the five density functionals, the Def2TZVP basis set, and water as the solvent.

\begin{tabular}{|c|c|c|c|c|c|c|c|}
\hline \multicolumn{8}{|c|}{ CAM-B3LYP } \\
\hline Molecule & HOMO & LUMO & SOMO & $J_{I}$ & $J_{A}$ & $J_{H L}$ & $\Delta S L$ \\
\hline Astaxanthin & -5.78 & -1.68 & -3.84 & 1.16 & 1.04 & 1.56 & 2.16 \\
\hline$\beta$-Cryptoxanthin & -5.62 & -1.40 & -3.71 & 1.13 & 1.14 & 1.60 & 2.31 \\
\hline Fucoxanthin & -5.90 & -1.56 & -3.94 & 1.21 & 1.17 & 1.68 & 2.37 \\
\hline Myxol & -5.48 & -1.63 & -3.97 & 1.16 & 1.16 & 1.64 & 2.34 \\
\hline Siphonaxanthin & -5.86 & -1.67 & -4.05 & 1.24 & 1.19 & 1.71 & 2.38 \\
\hline Siphonein & -5.90 & -1.62 & -4.04 & 1.22 & 1.19 & 1.71 & 2.41 \\
\hline Zeaxanthin & -5.60 & -1.42 & -3.74 & 1.13 & 1.14 & 1.61 & 2.31 \\
\hline
\end{tabular}


TABLE 4: Continued.

\begin{tabular}{|c|c|c|c|c|c|c|c|}
\hline \multicolumn{8}{|c|}{ CAM-B3LYP } \\
\hline Molecule & HOMO & LUMO & SOMO & $J_{I}$ & $J_{A}$ & $J_{H L}$ & $\Delta S L$ \\
\hline \multicolumn{8}{|c|}{$L C-\omega H P B E$} \\
\hline Astaxanthin & -6.96 & -0.91 & -5.01 & 2.20 & 1.99 & 2.97 & 4.10 \\
\hline$\beta$-Cryptoxanthin & -6.83 & -0.66 & -4.91 & 2.14 & 2.11 & 3.00 & 4.25 \\
\hline Fucoxanthin & -7.10 & -0.79 & -5.14 & 2.23 & 2.16 & 3.11 & 4.35 \\
\hline Myxol & -6.69 & -0.89 & -5.19 & 2.22 & 2.18 & 3.11 & 4.31 \\
\hline Siphonaxanthin & -7.06 & -0.89 & -5.26 & 2.28 & 2.21 & 3.17 & 4.37 \\
\hline Siphonein & -7.11 & -0.85 & -5.27 & 2.25 & 2.22 & 3.16 & 4.42 \\
\hline Zeaxanthin & -6.81 & -0.68 & -4.94 & 2.15 & 2.12 & 3.02 & 4.26 \\
\hline \multicolumn{8}{|c|}{$M N 12 S X$} \\
\hline Astaxanthin & -4.81 & -3.08 & -3.09 & 0.01 & 0.00 & 0.01 & 0.01 \\
\hline$\beta$-Cryptoxanthin & -4.61 & -2.76 & -2.79 & 0.01 & 0.01 & 0.01 & 0.03 \\
\hline Fucoxanthin & -4.89 & -2.96 & -2.98 & 0.01 & 0.01 & 0.02 & 0.02 \\
\hline Myxol & -4.50 & -2.99 & -3.03 & 0.01 & 0.02 & 0.02 & 0.04 \\
\hline Siphonaxanthin & -4.86 & -3.06 & -3.09 & 0.02 & 0.01 & 0.02 & 0.03 \\
\hline Siphonein & -4.90 & -3.02 & -3.04 & 0.01 & 0.01 & 0.02 & 0.02 \\
\hline Zeaxanthin & -4.58 & -2.79 & -2.82 & 0.01 & 0.02 & 0.02 & 0.03 \\
\hline \multicolumn{8}{|c|}{ N12SX } \\
\hline Astaxanthin & -4.58 & -2.89 & -2.93 & 0.05 & 0.02 & 0.06 & 0.04 \\
\hline$\beta$-Cryptoxanthin & -4.37 & -2.56 & -2.65 & 0.04 & 0.04 & 0.06 & 0.09 \\
\hline Fucoxanthin & -4.66 & -2.78 & -2.85 & 0.05 & 0.04 & 0.07 & 0.08 \\
\hline Myxol & -4.27 & -2.79 & -2.89 & 0.05 & 0.06 & 0.0 & 0.10 \\
\hline Siphonaxanthin & -4.63 & -2.87 & -2.96 & 0.06 & 0.05 & 0.08 & 0.09 \\
\hline Siphonein & -4.66 & -2.83 & -2.92 & 0.07 & 0.05 & 0.07 & 0.08 \\
\hline Zeaxanthin & -4.35 & -2.59 & -2.69 & 0.04 & 0.05 & 0.06 & 0.10 \\
\hline \multicolumn{8}{|c|}{$\omega B 97 X D$} \\
\hline Astaxanthin & -6.33 & -1.23 & -4.37 & 1.6453 & 1.51 & 2.25 & 3.13 \\
\hline$\beta$-Cryptoxanthin & -6.18 & -0.952 & -4.24 & 1.6049 & 1.62 & 2.28 & 3.28 \\
\hline Fucoxanthin & -6.47 & -1.11 & -4.48 & 1.6977 & 1.66 & 2.37 & 3.37 \\
\hline Myxol & -6.05 & -1.18 & -4.50 & 1.6387 & 1.64 & 2.32 & 3.32 \\
\hline Siphonaxanthin & -6.43 & -1.21 & -4.59 & 1.7358 & 1.67 & 2.41 & 3.38 \\
\hline Siphonein & -6.47 & -1.17 & -4.58 & 1.7136 & 1.68 & 2.40 & 3.41 \\
\hline Zeaxanthin & -6.16 & -0.97 & -4.26 & 1.6148 & 1.62 & 2.29 & 3.29 \\
\hline
\end{tabular}

TABLE 5: Free energy of solvation of the carotenoids (in Kcal/mol) calculated with the MN12SX and N12SX density functionals and the Def2TZVP basis set using hexane, methanol, ethanol, and water as the solvents, simulated with the SMD parametrization of the IEF-PCM model.

\begin{tabular}{|c|c|c|c|c|}
\hline \multicolumn{5}{|c|}{ MN12SX } \\
\hline Molecule & Hexane & Methanol & Ethanol & Water \\
\hline Astaxanthin & -24.59 & -31.79 & -31.84 & -16.56 \\
\hline$\beta$-Cryptoxanthin & -22.20 & -24.54 & -25.08 & -5.53 \\
\hline Fucoxanthin & -24.83 & -37.73 & -37.06 & -21.66 \\
\hline Myxol & -24.55 & -35.28 & -35.03 & -17.37 \\
\hline Siphonaxanthin & -24.25 & -36.66 & -36.09 & -20.55 \\
\hline Siphonein & -30.26 & -38.97 & -38.79 & -16.13 \\
\hline Zeaxanthin & -23.10 & -29.80 & -29.94 & -11.91 \\
\hline \multicolumn{5}{|c|}{ N12SX } \\
\hline Astaxanthin & -24.67 & -31.48 & -31.61 & -16.24 \\
\hline$\beta$-Cryptoxanthin & -22.35 & -24.79 & -25.34 & -5.78 \\
\hline Fucoxanthin & -24.82 & -36.92 & -36.37 & -20.82 \\
\hline Myxol & -24.61 & -34.86 & -34.68 & -16.93 \\
\hline Siphonaxanthin & -24.30 & -36.21 & -35.72 & -20.07 \\
\hline Siphonein & -30.32 & -38.47 & -38.40 & -15.61 \\
\hline Zeaxanthin & -23.20 & -29.69 & -29.88 & -11.79 \\
\hline
\end{tabular}


TABLE 6: Global reactivity descriptors (in eV) for the astaxanthin pigment calculated with the MN12SX and N12SX density functionals and the Def2TZVP basis set using the four solvents, simulated with the SMD parametrization of the IEF-PCM model.

\begin{tabular}{|c|c|c|c|c|c|c|}
\hline \multicolumn{7}{|c|}{ MN12SX } \\
\hline Molecule & Electronegativity & Global hardness & Electrophilicity & Electrodonating power & Electroaccepting power & Net electrophilicity \\
\hline Hexane & 4.06 & 1.76 & 4.68 & 11.49 & 7.44 & 18.93 \\
\hline Methanol & 3.95 & 1.74 & 4.49 & 11.07 & 7.12 & 18.19 \\
\hline Ethanol & 3.94 & 1.74 & 4.47 & 11.02 & 7.08 & 18.10 \\
\hline Water & 3.95 & 1.73 & 4.49 & 11.06 & 7.11 & 18.17 \\
\hline \multicolumn{7}{|c|}{ N12SX } \\
\hline Hexane & 3.84 & 1.72 & 4.28 & 10.58 & 6.74 & 17.32 \\
\hline Methanol & 3.74 & 1.70 & 4.11 & 10.20 & 6.47 & 16.67 \\
\hline Ethanol & 3.73 & 1.70 & 4.09 & 10.16 & 6.43 & 16.58 \\
\hline Water & 3.73 & 1.69 & 4.11 & 10.20 & 6.47 & 16.66 \\
\hline
\end{tabular}

TABLE 7: Global reactivity descriptors (in eV) for the $\beta$-cryptoxanthin pigment calculated with the MN12SX and N12SX density functionals and the Def2TZVP basis set using the four solvents, simulated with the SMD parametrization of the IEF-PCM model.

\section{MN12SX}

Molecule Electronegativity Global hardness Electrophilicity Electrodonating power Electroaccepting power Net electrophilicity

\begin{tabular}{|c|c|c|c|c|c|c|}
\hline Hexane & 3.61 & 1.84 & 3.54 & 9.00 & 5.39 & 14.39 \\
\hline Methanol & 3.68 & 1.84 & 3.66 & 9.28 & 5.60 & 14.89 \\
\hline Ethanol & 3.67 & 1.84 & 3.66 & 9.26 & 5.59 & 14.85 \\
\hline Water & 3.68 & 1.85 & 3.68 & 9.31 & 5.63 & 14.94 \\
\hline \multicolumn{7}{|c|}{ N12SX } \\
\hline Hexane & 3.39 & 1.81 & 3.17 & 8.15 & 4.77 & 12.92 \\
\hline Methanol & 3.46 & 1.81 & 3.31 & 8.46 & 5.00 & 13.45 \\
\hline Ethanol & 3.45 & 1.81 & 3.30 & 8.44 & 4.98 & 13.42 \\
\hline Water & 3.47 & 1.81 & 3.32 & 8.49 & 5.02 & 13.51 \\
\hline
\end{tabular}

TABLE 8: Global reactivity descriptors (in eV) for the fucoxanthin pigment calculated with the MN12SX and N12SX density functionals and the Def2TZVP basis set using the four solvents, simulated with the SMD parametrization of the IEF-PCM model.

\section{MN12SX}

Molecule Electronegativity Global hardness Electrophilicity Electrodonating power Electroaccepting power Net electrophilicity

\begin{tabular}{|c|c|c|c|c|c|c|}
\hline Hexane & 3.96 & 1.96 & 4.00 & 10.10 & 6.14 & 16.24 \\
\hline Methanol & 3.93 & 1.93 & 3.99 & 10.07 & 6.15 & 16.22 \\
\hline Ethanol & 3.92 & 1.94 & 3.96 & 10.01 & 6.09 & 16.09 \\
\hline Water & 3.93 & 1.93 & 4.00 & 10.08 & 6.15 & 16.24 \\
\hline \multicolumn{7}{|c|}{ N12SX } \\
\hline Hexane & 3.75 & 1.92 & 3.66 & 9.32 & 5.57 & 14.89 \\
\hline Methanol & 3.72 & 1.89 & 3.67 & 9.31 & 5.59 & 14.90 \\
\hline Ethanol & 3.71 & 1.89 & 3.64 & 9.24 & 5.53 & 14.78 \\
\hline Water & 3.72 & 1.89 & 3.67 & 9.32 & 5.60 & 14.92 \\
\hline
\end{tabular}

TABLE 9: Global reactivity descriptors for the myxol pigment calculated with the MN12SX and N12SX density functionals and the Def2TZVP basis set using the four solvents, simulated with the SMD parametrization of the IEF-PCM model.

\begin{tabular}{|c|c|c|c|c|c|c|}
\hline \multicolumn{7}{|c|}{ MN12SX } \\
\hline Molecule & Electronegativity & Global hardness & Electrophilicity & Electrodonating power & Electroaccepting power & Net electrophilicity \\
\hline Hexane & 3.72 & 1.51 & 4.59 & 11.13 & 7.41 & 18.53 \\
\hline Methanol & 3.74 & 1.51 & 4.62 & 11.20 & 7.46 & 18.67 \\
\hline Ethanol & 3.74 & 1.51 & 4.61 & 11.18 & 7.45 & 18.63 \\
\hline Water & 3.74 & 1.51 & 4.63 & 11.23 & 7.48 & 18.71 \\
\hline \multicolumn{7}{|c|}{ N12SX } \\
\hline Hexane & 3.50 & 1.48 & 4.13 & 10.11 & 6.61 & 16.72 \\
\hline Methanol & 3.52 & 1.48 & 4.19 & 10.23 & 6.70 & 16.93 \\
\hline Ethanol & 3.52 & 1.48 & 4.18 & 10.20 & 6.69 & 16.89 \\
\hline Water & 3.53 & 1.48 & 4.20 & 10.25 & 6.72 & 16.97 \\
\hline
\end{tabular}


TABLE 10: Global reactivity descriptors (in eV) for the siphonaxanthin pigment calculated with the MN12SX and N12SX density functionals and the Def2TZVP basis set using the four solvents, simulated with the SMD parametrization of the IEF-PCM model.

MN12SX

Molecule Electronegativity Global hardness Electrophilicity Electrodonating power Electroaccepting power Net electrophilicity

\begin{tabular}{|c|c|c|c|c|c|c|}
\hline Hexane & 4.03 & 1.82 & 4.47 & 11.06 & 7.03 & 18.09 \\
\hline Methanol & 3.96 & 1.80 & 4.37 & 10.83 & 6.87 & 17.69 \\
\hline Ethanol & 3.95 & 1.80 & 4.34 & 10.77 & 6.82 & 17.59 \\
\hline Water & 3.96 & 1.80 & 4.37 & 10.82 & 6.86 & 17.69 \\
\hline \multicolumn{7}{|c|}{ N12SX } \\
\hline Hexane & 3.82 & 1.78 & 4.10 & 10.21 & 6.39 & 16.61 \\
\hline Methanol & 3.75 & 1.75 & 4.01 & 10.01 & 6.26 & 16.27 \\
\hline Ethanol & 3.75 & 1.76 & 3.99 & 9.96 & 6.21 & 16.17 \\
\hline Water & 3.75 & 1.75 & 4.01 & 10.01 & 6.26 & 16.27 \\
\hline
\end{tabular}

TABLE 11: Global reactivity descriptors (in eV) for the siphonein pigment calculated with the MN12SX and N12SX density functionals and the Def2TZVP basis set using the four solvents, simulated with the SMD parametrization of the IEF-PCM model.

\begin{tabular}{|c|c|c|c|c|c|c|}
\hline \multicolumn{7}{|c|}{ MN12SX } \\
\hline Molecule & Electronegativity & Global hardness & Electrophilicity & Electrodonating power & Electroaccepting power & Net electrophilicity \\
\hline Hexane & 3.97 & 1.92 & 4.10 & 10.30 & 6.33 & 16.63 \\
\hline Methanol & 3.96 & 1.88 & 4.16 & 10.42 & 6.47 & 16.89 \\
\hline Ethanol & 3.95 & 1.89 & 4.13 & 10.35 & 6.40 & 16.75 \\
\hline Water & 3.96 & 1.88 & 4.17 & 10.44 & 6.48 & 16.92 \\
\hline \multicolumn{7}{|c|}{ N12SX } \\
\hline Hexane & 3.75 & 1.88 & 3.76 & 9.51 & 5.75 & 15.26 \\
\hline Methanol & 3.74 & 1.83 & 3.83 & 9.64 & 5.89 & 15.53 \\
\hline Ethanol & 3.73 & 1.84 & 3.79 & 9.56 & 5.83 & 15.39 \\
\hline Water & 3.75 & 1.83 & 3.83 & 9.65 & 5.91 & 15.56 \\
\hline
\end{tabular}

TABLE 12: Global reactivity descriptors (in eV) for the zeaxanthin pigment calculated with the MN12SX and N12SX density functionals and the Def2TZVP basis set using the four solvents, simulated with the SMD parametrization of the IEF-PCM model.

\section{MN12SX}

Molecule Electronegativity Global hardness Electrophilicity Electrodonating power Electroaccepting power Net electrophilicity

\begin{tabular}{|c|c|c|c|c|c|c|}
\hline Hexane & 3.65 & 1.79 & 3.73 & 9.40 & 5.75 & 15.16 \\
\hline Methanol & 3.68 & 1.79 & 3.78 & 9.52 & 5.84 & 15.36 \\
\hline Ethanol & 3.68 & 1.79 & 3.78 & 9.51 & 5.83 & 15.33 \\
\hline Water & 3.69 & 1.79 & 3.79 & 9.54 & 5.86 & 15.40 \\
\hline \multicolumn{7}{|c|}{ N12SX } \\
\hline Hexane & 3.43 & 1.75 & 3.35 & 8.52 & 5.10 & 13.62 \\
\hline Methanol & 3.46 & 1.76 & 3.41 & 8.67 & 5.21 & 13.88 \\
\hline Ethanol & 3.46 & 1.76 & 3.41 & 8.66 & 5.20 & 13.85 \\
\hline Water & 3.47 & 1.76 & 3.42 & 8.69 & 5.23 & 13.92 \\
\hline
\end{tabular}

TABLE 13: Nucleophilicity index $\mathrm{N}$ of the carotenoids (in eV) calculated with the MN12SX and N12SX density functionals and the Def2TZVP basis set using hexane, methanol, ethanol, and water as the solvents, simulated with the SMD parametrization of the IEF-PCM model.

\begin{tabular}{lcccc}
\hline & \multicolumn{2}{c}{ MN12SX } & & Ethanol \\
Molecule & Hexane & Methanol & 4.02 & \\
\hline Astaxanthin & 4.28 & 3.99 & 4.23 & 3.98 \\
B-Cryptoxanthin & 4.69 & 4.21 & 3.94 & \\
Fucoxanthin & 4.28 & 3.92 & 4.34 & 3.90 \\
Myxol & 4.75 & 4.31 & 3.98 & 3.29 \\
Siphonaxanthin & 4.28 & 3.95 & 3.94 & 3.93 \\
Siphonein & 4.29 & 3.91 & 4.26 & 4.21 \\
Zeaxanthin & 4.67 & 4.23 & & \\
\hline
\end{tabular}


TABle 13: Continued.

\begin{tabular}{|c|c|c|c|c|}
\hline \multicolumn{5}{|c|}{ MN12SX } \\
\hline Molecule & Hexane & Methanol & Ethanol & Water \\
\hline \multicolumn{5}{|c|}{ N12SX } \\
\hline Astaxanthin & 4.28 & 4.00 & 4.01 & 3.98 \\
\hline$\beta$-Cryptoxanthin & 4.69 & 4.22 & 3.93 & 4.19 \\
\hline Fucoxanthin & 4.27 & 3.92 & 4.23 & 3.90 \\
\hline Myxol & 4.75 & 4.32 & 4.33 & 4.29 \\
\hline Siphonaxanthin & 4.27 & 3.95 & 3.96 & 3.93 \\
\hline Siphonein & 4.29 & 3.92 & 3.94 & 3.90 \\
\hline Zeaxanthin & 4.68 & 4.24 & 4.25 & 4.21 \\
\hline
\end{tabular}

TABLE 14: Molecular properties of the seven carotenoid pigments calculated to verify the Lipinski's rule of five.

\begin{tabular}{lccccccrrr}
\hline Molecule & miLogP & TPSA & nAtoms & nON & nOHNH & nviol & nrotb & Volume & MW \\
\hline Astaxanthin & 8.60 & 74.60 & 44 & 4 & 2 & 2 & 10 & 612.41 & 596.85 \\
$\beta$-Cryptoxanthin & 9.64 & 20.23 & 41 & 1 & 1 & 2 & 10 & 600.01 & 552.89 \\
Fucoxanthin & 8.49 & 96.36 & 48 & 6 & 2 & 2 & 12 & 664.84 & 658.92 \\
Myxol & 9.17 & 60.68 & 43 & 3 & 3 & 2 & 13 & 620.72 & 584.88 \\
Siphonaxanthin & 8.32 & 77.75 & 44 & 4 & 3 & 2 & 12 & 624.71 & 600.88 \\
Siphonein & 9.96 & 83.83 & 57 & 5 & 2 & 2 & 23 & 823.05 & 781.17 \\
Zeaxanthin & 9.39 & 40.46 & 42 & 2 & 2 & 2 & 10 & 608.05 & 568.89 \\
\hline
\end{tabular}

TABLE 15: Bioactivity scores of the seven carotenoid pigments calculated on the basis of GPCR ligand, ion channel modulator, nuclear receptor ligand, kinase inhibitor, protease inhibitor, and enzyme inhibitor interactions.

\begin{tabular}{lcccccc}
\hline Molecule & $\begin{array}{c}\text { GPCR } \\
\text { ligand }\end{array}$ & $\begin{array}{c}\text { Ion channel } \\
\text { modulator }\end{array}$ & $\begin{array}{c}\text { Kinase } \\
\text { inhibitor }\end{array}$ & $\begin{array}{c}\text { Nuclear receptor } \\
\text { ligand }\end{array}$ & $\begin{array}{c}\text { Protease } \\
\text { inhibitor }\end{array}$ & $\begin{array}{c}\text { Enzyme } \\
\text { inhibitor }\end{array}$ \\
\hline Astaxanthin & -0.09 & -0.62 & -0.45 & 0.16 & 0.49 & 0.00 \\
$\beta$-Cryptoxanthin & -0.03 & -0.26 & -0.20 & -0.28 & 0.02 & 0.24 \\
Fucoxanthin & -0.44 & -1.04 & -1.03 & 0.37 & -0.05 & -0.36 \\
Myxol & -0.05 & -0.38 & -0.24 & 0.26 & 0.08 & -0.08 \\
Siphonaxanthin & -0.07 & -0.54 & -048 & -2.08 & -1.23 \\
Siphonein & -1.73 & -2.82 & -2.70 & 0.35 & -1.84 \\
Zeaxanthin & -0.08 & -0.36 & -0.24 & 0.13 \\
\hline
\end{tabular}

and zeaxanthin will be prone to act as nuclear receptor ligands, while fucoxanthin and siphonein will be moderately bioactive, regarding all the interactions.

\section{Conclusions}

In this paper, we have presented a new study performed on the chemical reactivity of seven carotenoid pigments of marine origin based on conceptual DFT as a tool to explain molecular interactions.

The knowledge of the values of the global and local descriptors of the molecular reactivity of the carotenoid pigments studied could be useful in the development of new drugs based on these compounds or some analogs. On the basis of the analysis of the electrophilicity index $\omega$ and Domingo's nucleophilicity index $\mathrm{N}$, it could be concluded that the studied carotenoids display concurrently both strong electrophilic and nucleophilic behaviors.

Finally, the molecular properties related to bioavailability have been predicted using different methodologies already described in the literature, and the descriptors used for the quantification of the bioactivity allowed us to characterize some of the studied molecules as being bioactive by acting as ligands for a nuclear receptor.

\section{Data Availability}

All the data related to this submission are available upon request.

\section{Conflicts of Interest}

The authors declare that the research was conducted in the absence of any commercial or financial relationships that could be construed as potential conflicts of interest.

\section{Authors' Contributions}

Daniel Glossman-Mitnik conceived and designed the research and headed, wrote, and revised the manuscript, while Juan Frau and Norma Flores-Holguín contributed to the writing and revision of the article. 


\section{Acknowledgments}

This work has been partially supported by CIMAV, SC, and Consejo Nacional de Ciencia y Tecnología (CONACYT, Mexico) through Grant 219566-2014 for Basic Science Research. Daniel Glossman-Mitnik conducted this work while being a visiting lecturer at the University of the Balearic Islands, from which support is gratefully acknowledged. Norma Flores-Holguín and Daniel Glossman-Mitnik are researchers of CIMAV and CONACYT. This work was cofunded by the Ministerio de Economía y Competitividad (MINECO) and the European Fund for Regional Development (FEDER) (CTQ2014-55835-R).

\section{References}

[1] J. T. Landrum, Carotenoids-Physical, Chemical, and Biological Functions and Properties, CRC Press-Taylor \& Francis Group, Boca Raton, FL, USA, 2010.

[2] M. Faustino, M. Veiga, P. Sousa, E. M. Costa, S. Silva, and M. Pintado, "Agro-food byproducts as a new source of natural food additives," Molecules, vol. 24, no. 6, article 1056, 2019.

[3] E. Yamazaki, M. Murayama, N. Nishikawa, N. Hashimoto, M. Shoyama, and O. Kurita, "Utilization of natural carotenoids as photosensitizers for dye-sensitized solar cells," Solar Energy, vol. 81, no. 4, pp. 512-516, 2007.

[4] T. Ruiz-Anchondo and D. Glossman-Mitnik, "Computational characterization of the $\beta, \beta$-carotene molecule," Journal of Molecular Structure: THEOCHEM, vol. 913, no. 1-3, pp. 215-220, 2009.

[5] T. Ruiz-Anchondo, N. Flores-Holguín, and D. GlossmanMitnik, "Natural carotenoids as nanomaterial precursors for molecular photovoltaics: a computational DFT study," Molecules, vol. 15, no. 7, pp. 4490-4510, 2010.

[6] M. Flores-Hidalgo, F. Torres-Rivas, J. Monzón-Bensojo, M. Escobedo-Bretado, D. Glossman-Mitnik, and D. BarrazaJiménez, "Electronic structure of carotenoids in natural and artificial photosynthesis," in Carotenoids, D. J. Cvetkovic and G. S. Nikolic, Eds., InTech, Rijeka, Croatia, pp. 17-33, 2017.

[7] S.-K. Kim, Marine Pharmacognosy-Trends and Application, CRC Press, Boca Raton, FL, USA, 2013.

[8] S. La Barre and J.-M. Kornprobst, Outstanding Marine Molecules, Wiley-Blackwell, Weinheim, Germany, 2014.

[9] C. Galasso, C. Corinaldesi, and C. Sansone, "Carotenoids from marine organisms: biological functions and industrial applications," Antioxidants, vol. 6, no. 4, p. 96, 2017.

[10] C. Vilchez, E. Forján, M. Cuaresma, F. Bédmar, I. Garbayo, and J. Vega, "Marine carotenoids: biological functions and commercial applications," Marine Drugs, vol. 9, no. 3, pp. 319-333, 2011.

[11] G. L. Patrick, An Introduction to Medicinal Chemistry, Oxford University Press, Oxford, UK, 2013.

[12] E. Rekka and P. Kourounakis, Chemistry and Molecular Aspects of Drug Design and Action, CRC Press, Boca Raton, 2008.

[13] G. Náray-Szabó and A. Warshel, Computational Approaches to Biochemical Reactivity, Kluwer Academic Publishers, New York, NY, USA, 2002.

[14] R. Parr and W. Yang, Density-Functional Theory of Atoms and Molecules, Oxford University Press, New York, NY, USA, 1989.

[15] P. Geerlings, F. De Proft, and W. Langenaeker, "Conceptual density functional theory," Chemical Reviews, vol. 103, no. 5, pp. 1793-1874, 2003.
[16] K. Stromgaard, P. Krogsgaard-Larsen, and U. Madsen, Textbook of Drug Design and Discovery, CRC Press-Taylor \& Francis Group, Boca Raton, FL, USA, 2017.

[17] G. K. Gupta and V. Kumar, Chemical Drug Design, Walter de Gruyter GmbH, Berlin, Germany, 2016.

[18] M. Gore and U. B. Jagtap, Computational Drug Discovery and Design, Springer Science+Business Media, LLC, New York, NY, USA, 2018.

[19] J. Frau and D. Glossman-Mitnik, "Molecular reactivity and absorption properties of melanoidin blue-G1 through conceptual DFT," Molecules, vol. 23, no. 3, pp. 559-615, 2018.

[20] J. Frau and D. Glossman-Mitnik, "Conceptual DFT study of the local chemical reactivity of the dilysyldipyrrolones A and B intermediate melanoidins," Theoretical Chemistry Accounts, vol. 137, no. 5, p. 1210, 2018.

[21] J. Frau and D. Glossman-Mitnik, "Conceptual DFT study of the local chemical reactivity of the colored BISARG melanoidin and its protonated derivative," Frontiers in Chemistry, vol. 6, pp. 1-9, 2018.

[22] J. Frau and D. Glossman-Mitnik, "Molecular reactivity of some maillard reaction products studied through conceptual DFT,” ContemporaryChemistry, vol. 1, pp. 1-14, 2018.

[23] J. Frau and D. Glossman-Mitnik, "Computational study of the chemical reactivity of the Blue-M1 intermediate melanoidin," Computational and Theoretical Chemistry, vol. 1134, pp. 2229, 2018.

[24] J. Frau and D. Glossman-Mitnik, "Chemical reactivity theory applied to the calculation of the local reactivity descriptors of a colored maillard reaction product," Chemical Science International Journal, vol. 22, no. 4, pp. 1-14, 2018.

[25] J. Frau and D. Glossman-Mitnik, "Blue M2: an intermediate melanoidin studied via conceptual DFT," Journal of Molecular Modeling, vol. 24, no. 6, pp. 1-13, 2018.

[26] J. Frau, N. Flores-Holguín, and D. Glossman-Mitnik, "Chemical reactivity properties, pKa values, AGEs inhibitor abilities and bioactivity scores of the mirabamides A-H peptides of marine origin studied by means of conceptual DFT," Marine Drugs, vol. 16, no. 9, pp. 302-319, 2018.

[27] N. Flores-Holguín, J. Frau, and D. Glossman-Mitnik, "Chemical reactivity properties, drug-likeness features and bioactivity scores of the cholecystokinin peptide hormone," Computational Molecular Bioscience, vol. 9, no. 2, pp. 41-47, 2019.

[28] N. Flores-Holguín, J. Frau, and D. Glossman-Mitnik, "Chemical reactivity properties and bioactivity scores of the angiotensin II vasoconstrictor octapeptide," in Cheminformatics and its Applications, A. Stefaniu, Ed., IntechOpen, Rijeka, Croatia, pp. 1-8, 2019.

[29] M. J. Frisch, Gaussian 09 Revision E.01. 2016, Gaussian Inc., Wallingford, CT, USA, 2016.

[30] R. Peverati and D. G. Truhlar, "Screened-exchange density functionals with broad accuracy for chemistry and solid-state physics," Physical Chemistry Chemical Physics, vol. 14, no. 47, pp. 16187-16191, 2012.

[31] F. Weigend and R. Ahlrichs, "Balanced basis sets of split valence, triple zeta valence and quadruple zeta valence quality for H to Rn: design and assessment of accuracy," Physical Chemistry Chemical Physics, vol. 7, no. 18, pp. 3297-3305, 2005.

[32] F. Weigend, "Accurate Coulomb-fitting basis sets for $\mathrm{H}$ to Rn,” Physical Chemistry Chemical Physics, vol. 8, no. 9, pp. 1057-1065, 2006.

[33] A. V. Marenich, C. J. Cramer, and D. G. Truhlar, "Universal solvation model based on solute electron density and on 
a continuum model of the solvent defined by the bulk dielectric constant and atomic surface tensions," The Journal of Physical Chemistry B, vol. 113, no. 18, pp. 6378-6396, 2009.

[34] R. G. Parr, L. V. Szentpály, and S. Liu, "Electrophilicity index," Journal of the American Chemical Society, vol. 121, no. 9, pp. 1922-1924, 1999.

[35] J. L. Gázquez, A. Cedillo, and A. Vela, "Electrodonating and electroaccepting powers," The Journal of Physical Chemistry A, vol. 111, no. 10, pp. 1966-1970, 2007.

[36] P. K. Chattaraj, A. Chakraborty, and S. Giri, "Net electrophilicity," The Journal of Physical Chemistry A, vol. 113, no. 37, pp. 10068-10074, 2009.

[37] L. Domingo, M. Ríos-Gutiérrez, and P. Pérez, "Applications of the conceptual density functional theory indices to organic chemistry reactivity," Molecules, vol. 21, no. 6, p. 748, 2016.

[38] L. R. Domingo, M. J. Aurell, P. Pérez, and R. Contreras, "Quantitative characterization of the global electrophilicity power of common diene/dienophile pairs in Diels-Alder reactions," Tetrahedron, vol. 58, no. 22, pp. 4417-4423, 2002.

[39] P. Pérez, L. R. Domingo, M. José Aurell, and R. Contreras, "Quantitative characterization of the global electrophilicity pattern of some reagents involved in 1,3-dipolar cycloaddition reactions," Tetrahedron, vol. 59, no. 17, pp. 3117-3125, 2003.

[40] L. R. Domingo and J. A. Sáez, "Understanding the mechanism of polar Diels-Alder reactions," Organic \& Biomolecular Chemistry, vol. 7, no. 17, pp. 3576-3583, 2009.

[41] L. R. Domingo and P. Pérez, "The nucleophilicity N index in organic chemistry," Organic \& Biomolecular Chemistry, vol. 9, no. 20 , pp. $7168-7175,2011$.

[42] L. R. Domingo, E. Chamorro, and P. Pérez, "Understanding the reactivity of captodative ethylenes in polar cycloaddition reactions: a theoretical study," The Journal of Organic Chemistry, vol. 73, no. 12, pp. 4615-4624, 2008.

[43] P. Jaramillo, L. R. Domingo, E. Chamorro, and P. Pérez, "A further exploration of a nucleophilicity index based on the gas-phase ionization potentials," Journal of Molecular Structure: THEOCHEM, vol. 865, no. 1-3, pp. 68-72, 2008.

[44] C. A. Lipinski, F. Lombardo, B. W. Dominy, and P. J. Feeney, "Experimental and computational approaches to estimate solubility and permeability in drug discovery and development settings," Advanced Drug Delivery Reviews, vol. 46, no. $1-3$, pp. 3-26, 2001.

[45] P. Leeson, "Chemical beauty contest," Nature, vol. 481, no. 7382, pp. 455-456, 2012. 

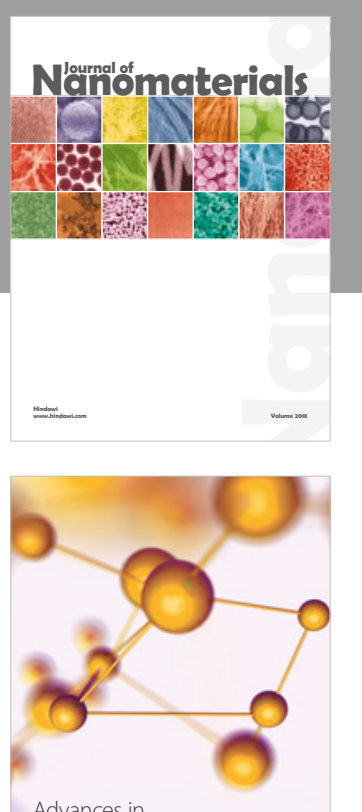

Physical Chemistry
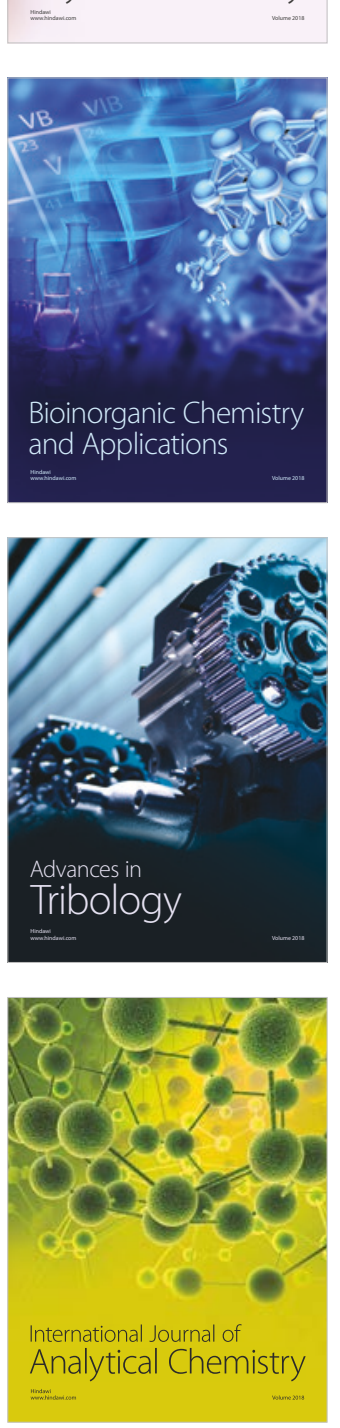

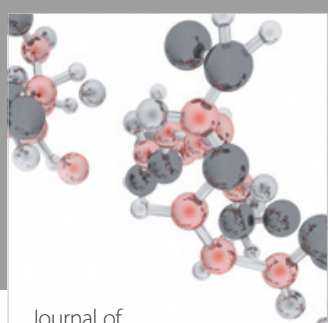

Analytical Methods

in Chemistry

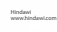

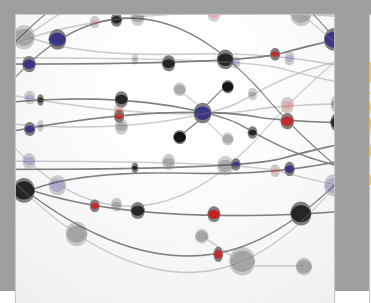

The Scientific World Journal

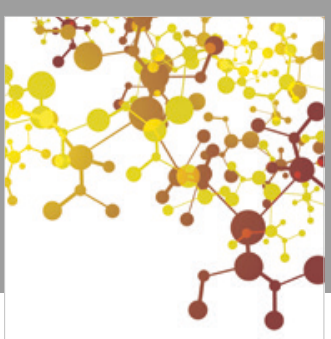

Journal of

Applied Chemistry
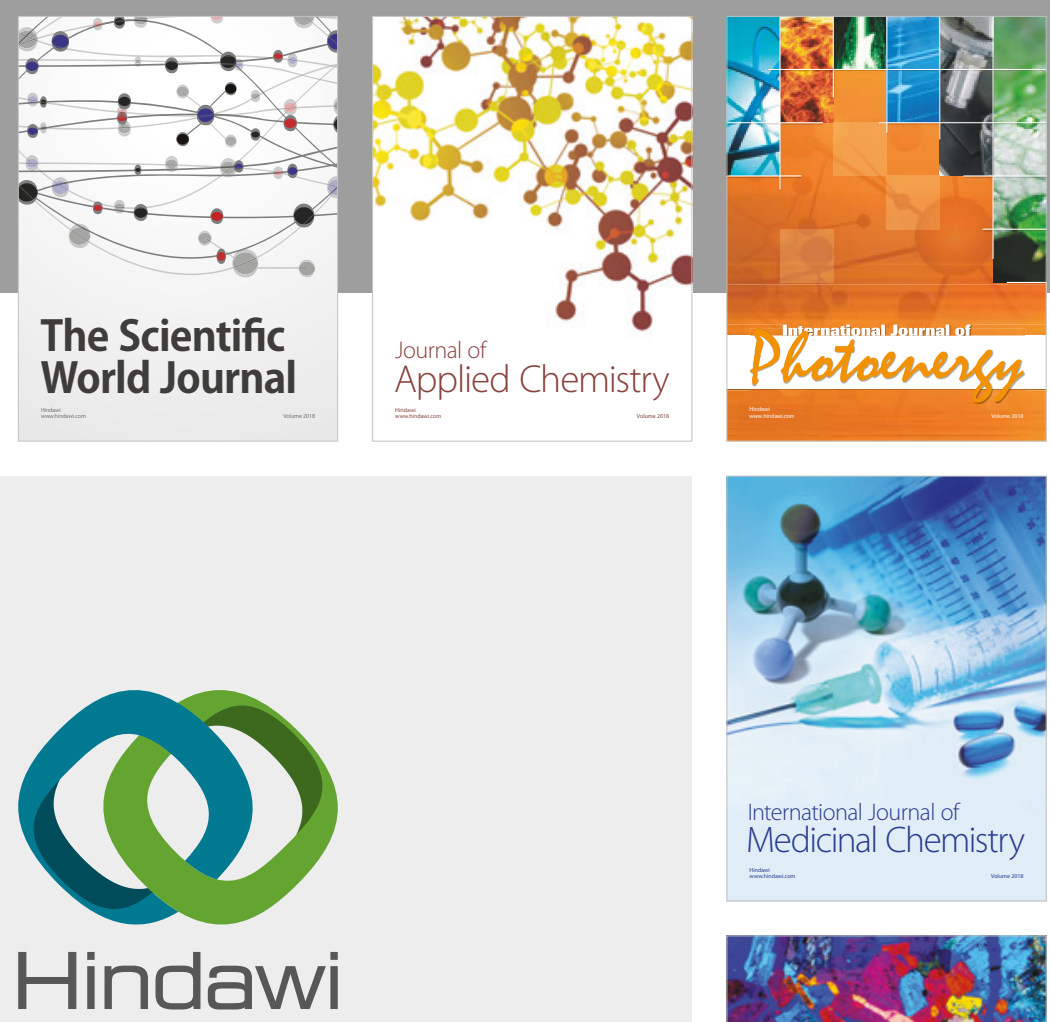

Submit your manuscripts at

www.hindawi.com
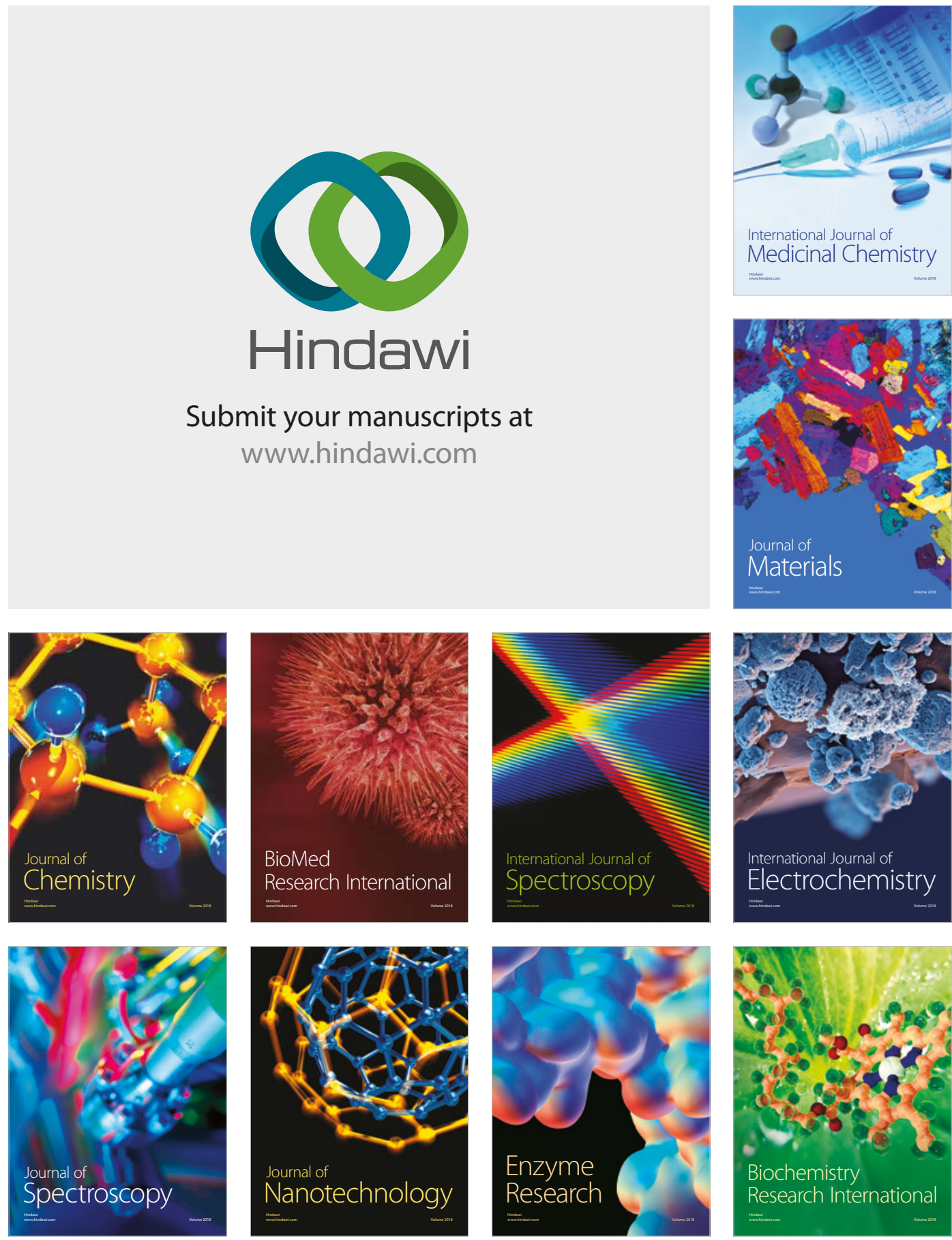
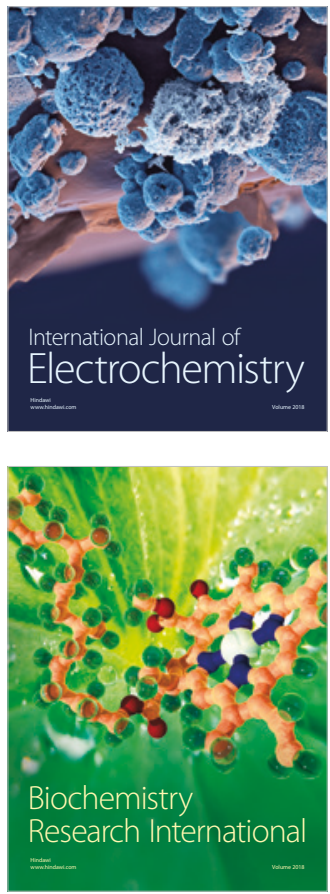